\title{
RHIC Spin flipper, fast-sweep efficiency simulations
}

\author{
F. Meot, H. Huang, J. Kewisch, \\ P. Oddo, G. Robert-Demolaize, T. Roser
}

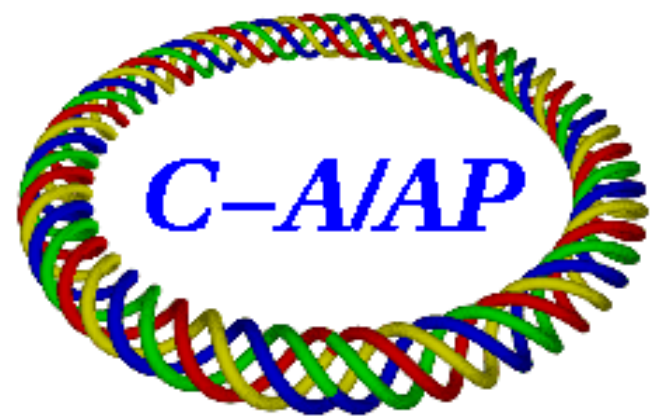

Collider-Accelerator Department Brookhaven National Laboratory Upton, N.Y. 11973

\author{
U.S. Department of Energy \\ Office of Science, Office of Nuclear Physics
}

Notice: This document has been authorized by employees of Brookhaven Science Associates, LLC under Contract No. DE-SC0012704 with the U.S. Department of Energy. The United States Government retains a non- exclusive, paid-up, irrevocable, world-wide license to publish or reproduce the published form of this document, or allow others to do so, for United States Government purposes. 


\section{DISCLAIMER}

This report was prepared as an account of work sponsored by an agency of the United States Government. Neither the United States Government nor any agency thereof, nor any of their employees, nor any of their contractors, subcontractors, or their employees, makes any warranty, express or implied, or assumes any legal liability or responsibility for the accuracy, completeness, or any third party's use or the results of such use of any information, apparatus, product, or process disclosed, or represents that its use would not infringe privately owned rights. Reference herein to any specific commercial product, process, or service by trade name, trademark, manufacturer, or otherwise, does not necessarily constitute or imply its endorsement, recommendation, or favoring by the United States Government or any agency thereof or its contractors or subcontractors. The views and opinions of authors expressed herein do not necessarily state or reflect those of the United States Government or any agency thereof. 


\title{
RHIC spin flipper, fast-sweep efficiency simulations
}

\author{
F. Méot, H. Huang, J. Kewisch, P. Oddo, G. Robert-Demolaize, T. Roser
}

Collider-Accelerator Department, BNL, Upton, NY 11973

August 8, 2017

\begin{abstract}
Polarization flip simulations have been performed during Run 17 in parallel to resuming spin flipper experiments in RHIC. They are reported here, including some guidance they brought.
\end{abstract}

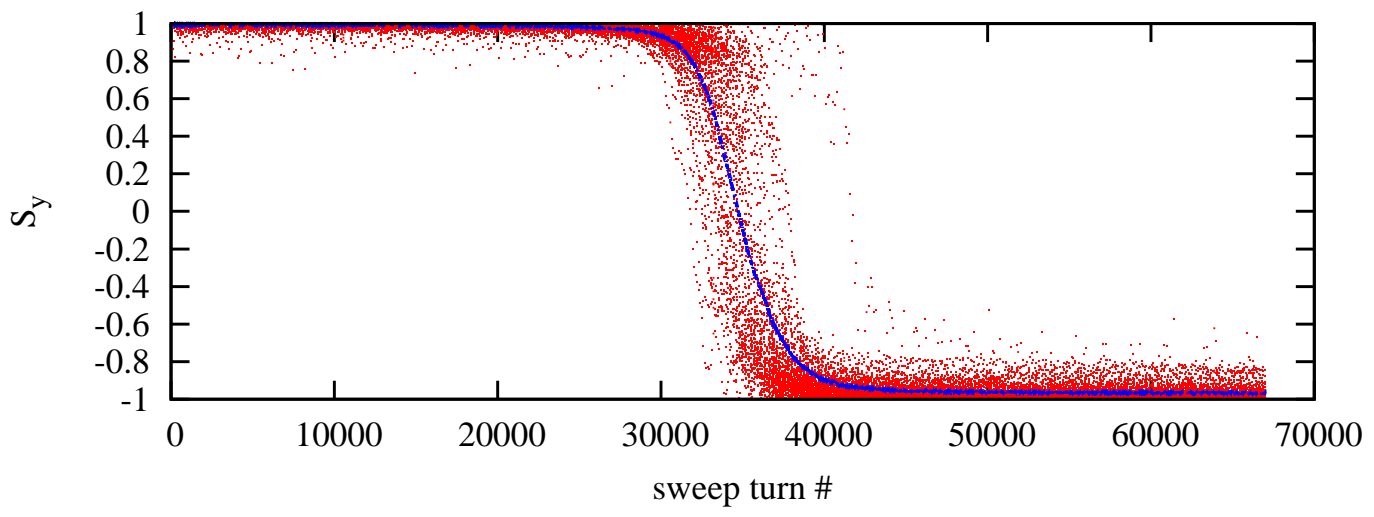

Tech. Note $C A / A P / 589$

$B N L C-A D$ 


\section{Contents}

1 Introduction

2 Spin flipper in RHIC, simulation conditions

3 Numerical outcomes

3.1 Injection $(\mathrm{G} \gamma=45.5)$

3.2 Store $(\mathrm{G} \gamma=487)$

. .

3.3 A summary table 


\section{Introduction}

Spin flip simulations in RHIC were performed in the May-June period during Run 17, in parallel with RHIC spin flipper experiments which were resumed during this very RHIC run.

These simulations have had two significant outcomes :

(i) increasing the AC dipole frequency sweep rate, by a substantial amount compared to the value initially used during the experiments, appears to improve the spin flip efficiency,

(ii) in the conditions of the simulations (e.g., defect-free ring; ideal snakes : $180^{\circ}$ spin rotation at $\pm 45^{\circ}$ from the longitudinal axis ; $180^{\circ}$ orbit angle between the two snakes opposing in RHIC diameter; perfect spin flipper setting including absence of image resonance, etc.), the difference in the dispersion derivative at the two snakes as a source of spin tune spread via the chromatic orbit angles at the snakes [1], subject to dedicated RHIC optics settings during Run 17 spin flipper experiment, does not seem of very stringent importance.

These two observations from the simulations were used as a guidance : the first one was confirmed experimentally, and there are indications from the experiments that the second observation holds.

Section 2 below recalls the principles of the spin flipper system in RHIC, and introduces the resulting input data to the simulations for the sake of clarity. Section 3 presents the main outcomes of these simulations, which Section 4 comments on.

\section{Spin flipper in RHIC, simulation conditions}

The spin flipper in RHIC is an interleave of four horizontal dipoles ("DC rotator" in Fig. 1) and five vertical AC dipoles (AC dipole\#1-5). It is located in the RHIC Blue ring, between "BI9_TQ4" and "BI9_QF3" quadrupoles.

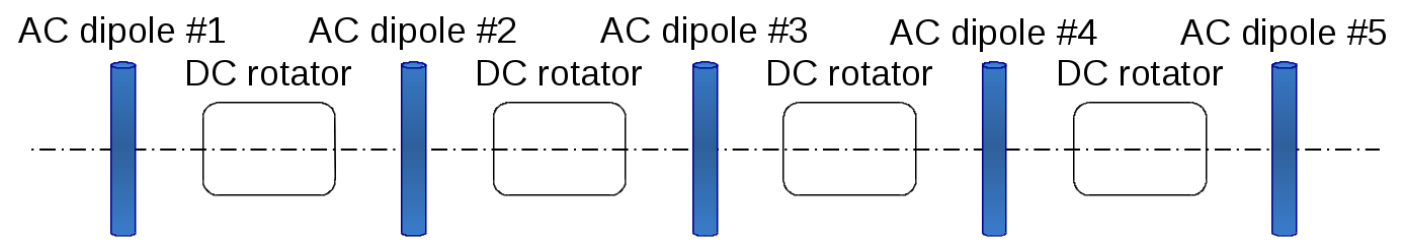

Figure 1: Layout of the spin flipper [1].

The principles of this spin flipper and its installation in RHIC are detailed and discussed in Refs. [1]-[5]. The 4 "spin rotator" dipoles are DC, they yield spin y-rotation angles $+/-/-/+\times \phi_{0}$ respectively, with

$$
\phi_{0}=(1+\mathrm{G} \gamma) \frac{\mathrm{BL}}{\mathrm{B} \rho}
$$

Orbit-wise this defines a closed local horizontal bump and, spin-wise, it leaves the spin tune $\mathrm{Q}_{\mathrm{s}}$ unchanged.

The 5 AC dipoles are operated at frequency $\mathrm{Q}_{\mathrm{osc}} \approx \mathrm{f}_{\mathrm{rev}} / 2$, with fractional part in the vicinity of $\mathrm{Q}_{\mathrm{s}}$. ACD1-3 and ACD3-5 ensure the same $+1 /-2 /+1 \times \psi_{\text {osc }}$ spin $\mathrm{X}$-rotation sequence,

$$
\psi_{\mathrm{osc}}=(1+\mathrm{G} \gamma) \frac{\mathrm{B}_{\mathrm{osc}} \mathrm{L}}{\mathrm{B} \rho}
$$

Orbit-wise, each triplet ensures a local vertical orbit bump. Fields in ACD 2 and 4 are $180^{\circ}+\phi_{0}$ distant in phase.

This configuration induces spin resonance at $\mathrm{Q}_{\mathrm{osc}}=\mathrm{Q}_{\mathrm{s}}$ while eliminating the image resonance at $1-\mathrm{Q}_{\mathrm{s}}$, therefore ensuring single resonance crossing during $\mathrm{Q}_{\mathrm{osc}}$ sweep through $\mathrm{Q}_{\mathrm{s}} \approx \frac{1}{2}$ and allowing full spin flip (isolated resonance crossing in the presence of image resonance instead, would otherwise require $Q_{\mathrm{S}}$ to be away enough from $\frac{1}{2}$ and $\mathrm{Q}_{\mathrm{osc}}$ excursion accordingly small).

The strength of this spin-resonance system is

$$
|\epsilon|=\frac{\psi_{\mathrm{osc}}}{\pi} \sin \phi_{0} \sin \frac{\phi_{0}}{2}
$$

The crossing speed (rate of sweep of $Q_{\text {osc }}$ through $Q_{\mathrm{s}} \approx \frac{1}{2}$ ) is

$$
\alpha=\frac{\Delta \mathrm{Q}_{\mathrm{osc}}}{\mathrm{d} \theta}, \quad \mathrm{d} \theta=2 \pi \mathrm{N}
$$

with $\Delta \mathrm{Q}_{\mathrm{osc}}$ the AC dipole frequency span and $\mathrm{N}$ the number of turns of the sweep. $\alpha$ has to be small enough ( $\mathrm{N}$ large enough) for spins to follow the flip of the spin precession axis so that the polarization states $\mathrm{P}_{\mathrm{f}}$ (final) and $\mathrm{P}_{\mathrm{i}}$ (initial) satisfy

$$
\frac{\mathrm{P}_{\mathrm{f}}}{\mathrm{P}_{\mathrm{i}}}=2 \exp -\frac{\pi}{2} \frac{|\epsilon|^{2}}{\alpha}-1 \approx-1
$$


D' lattice : Momentum dispersion induces spin tune spread, via

$$
\delta \mathrm{Q}_{\mathrm{s}}=\frac{\mathrm{G} \gamma}{\pi} \Delta \mathrm{D}^{\prime} \frac{\Delta \mathrm{p}}{\mathrm{p}}
$$

with $\Delta \mathrm{D}^{\prime}$ the difference in $\mathrm{D}^{\prime}$ at the two snakes [6]. This effect is considered a cause of loss of polarization during the frequency sweep, in particular by inducing multiple resonance crossing under the effect of synchrotron motion - following the sketch in page 7.

"D' lattice" optics are aimed at overcoming that effect, by ensuring minimized $\Delta \mathrm{D}^{\prime}$ during the ACD frequency sweep. They require dedicated, possibly lengthy, tunings based on the use of gamma transition quads [1].

Typically: $\delta \mathrm{Q}_{\mathrm{s}} / \frac{\Delta \mathrm{p}}{\mathrm{p}}=150 \times \Delta \mathrm{D}^{\prime}$ at $250 \mathrm{GeV}$, about 10 times less at injection. Thus, assuming $\delta \mathrm{p} / \mathrm{p}<10^{-3}$, reducing $\delta \mathrm{Q}_{\mathrm{s}}$ at $<10^{-3}$ level (namely, small enough by comparison with $\Delta \mathrm{Q}_{\mathrm{osc}}$, see sketch p. 7) requires a typical $\Delta \mathrm{D}^{\prime}<70 \mathrm{mrad}$ at injection, $\Delta \mathrm{D}^{\prime}<7 \mathrm{mrad}$ at store.

DC rotator and AC dipole settings in these simulations are consistent with (although not strictly identical to) Run 17 APEX conditions in RHIC, Table below.

Numerical simulation data (actual APEX conditions in column 5)

\begin{tabular}{lcccl}
\hline & & injection & store & \\
\hline G $\gamma$ & & 45.5 & 487 & \\
B $\rho$ & $($ T.m $)$ & 79.37 & 850.128 & \\
ACD strength & $($ G.m $)$ & 102 & 102 & APEX $: 100$ G.m \\
ACD $\psi_{\text {osc }}$ & $($ deg $)$ & 0.342 & 0.336 & \\
DC rotator $\phi_{0}$ & $(\mathrm{deg})$ & 29.9 & 44.9 & APEX $: 48.8^{\circ}$ at store \\
$|\epsilon|$ & $\left(10^{-4}\right)$ & 2.45 & 4.32 & \\
Q osc range & & $0.49-0.51$ & $0.49-0.51$ & APEX $: \Delta Q_{\text {osc }}=0.005$ \\
RF systems & $(\mathrm{MHz})$ & 9 or 28 & $9+197$ & APEX $: 9+197$ at injection and store \\
\hline
\end{tabular}

Details of RF conditions during APEX :

Blue $9 \mathrm{MHz}$ cavity is the main one for injection and acceleration. It is set at $22 \mathrm{kV}$ at injection and $30 \mathrm{kV}$ at store. The $28 \mathrm{MHz}$ (BA1 and BA2) are considered off. However $28 \mathrm{MHz}$ has been investigated in the simulations (not reported here - with a trend to loss of spin flip efficiency due to multiple crossing, sketch in page 7, also discussed in [7]).

The Landau cavities (BS1 and BS2) are $197 \mathrm{MHz}$ ones and voltage is around $10 \mathrm{kV}$ at injection, $15 \mathrm{kV}$ at store. These are the conditions as well for the double-RF simulations (see p. 11).

Detailed data for the rotator and AC dipoles in Zgoubi [8] are given in page 5. Details of RF conditions are given in due place together with the tracking outcomes (Sec. 3).

Zgoubi input/output files used in these studies can be found in

$$
\text { /rap/lattice_tools/zgoubi/RHICZgoubiModel/spinFlipper }
$$

C-AD server folders. 


\section{- ZGOUBI INPUT -}

\section{AC dipole sweep command :}

\section{- DC rotators and AC dipoles input data, injection :}

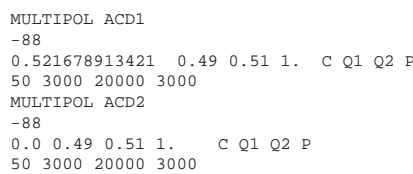

\section{Spin flipper sequence :}

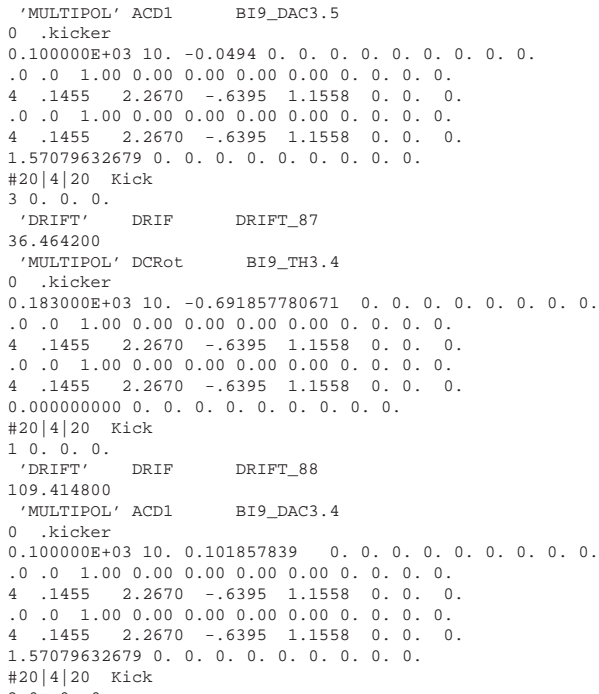

\section{AC dipole sweep command :}

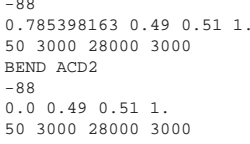

\section{Spin flipper sequence :}

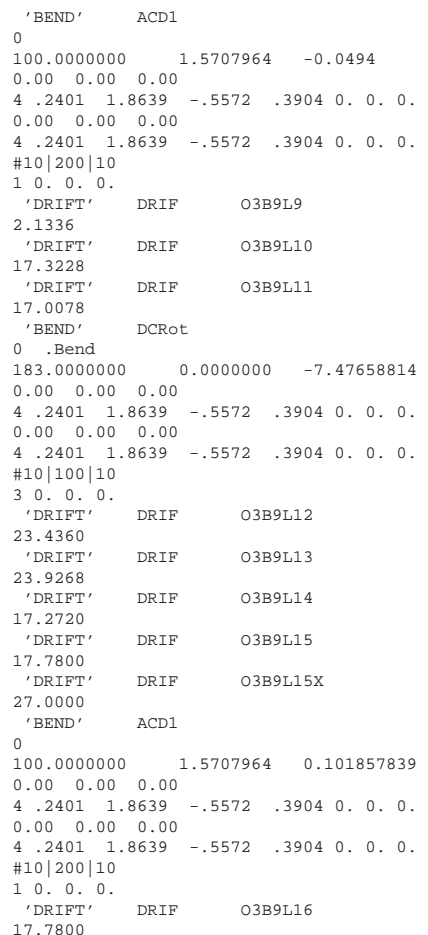

'DRIFT' DRIF DRIFT_89

'MULTIPOL' DCRot BI9_TH3.3

0 . kicker

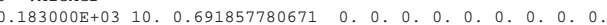

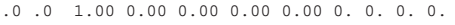

$\begin{array}{llllllll}4 & .1455 & 2.2670 & -.6395 & 1.1558 & 0 . & 0 . & 0\end{array}$

$\begin{array}{lllllllll}4 & .1455 & 2.2670 & -.6395 & 1.1558 & 0 . & 0 . & 0 .\end{array}$

0.000000000 0.0.0.0.0.0.0.0.0.

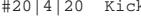

$1,0^{0},{ }^{0}$
DRIFT' DRIF DRIFT 90

63.415400

'MULTIPOL' ACD1 BI9_DAC3.3_1

0 . kicker

$\begin{array}{llllllllll}.0 & .0 & 1.00 & 0.00 & 0.00 & 0.00 & 0.00 & 0.0 .0 .0 .0 .0 & 0.0 .0\end{array}$

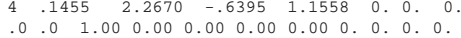

$\begin{array}{lllllllll}4.1455 & 2.2670 & -.6395 & 1.1558 & 0 . & 0 . & 0 .\end{array}$

1.570796326790 .0 .0 .0 .0 .0 .0 .0 .0$.

$\# 20|4| 20$ Kick

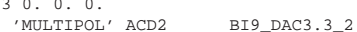

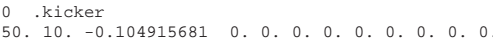

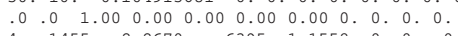

$\begin{array}{lllllllll}4 & .1455 & 2.2670 & -.6395 & 1.1558 & 0.0 . & 0 .\end{array}$

$\begin{array}{llllllllll}.0 & .0 & 1.00 & 0.00 & 0.00 & 0.00 & 0.00 & 0.0 .0 .0 .0 .0 & 0.0\end{array}$

$\begin{array}{llllllll}4 & .1455 & 2.2670 & -.6395 & 1.1558 & 0 . & 0 . & 0 .\end{array}$

1.570796326790 .

$\# 20|4| 20$ Kick

, ${ }^{3}$ DRIFT' ${ }^{\circ}$. DRIF DRIFT_87

36.464200

'MULTIPOL' DCRot BI9_TH3.2

0 .kicker

$0.183000 \mathrm{E}+0310.0 .691857780671 \quad 0.0 .0 .0 .0 .0 .0 .0 .0$.

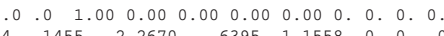

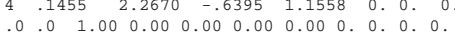

$\begin{array}{ccccccccccc}.0 & .0 & 1.00 & 0.00 & 0.00 & 0.00 & 0.00 & 0.0 & 0.0 . & 0 . \\ 4 & .1455 & 2.2670 & -.6395 & 1.1558 & 0.0 .0 & 0 .\end{array}$

0.0000000000.

$\# 20|4| 20$ Kick

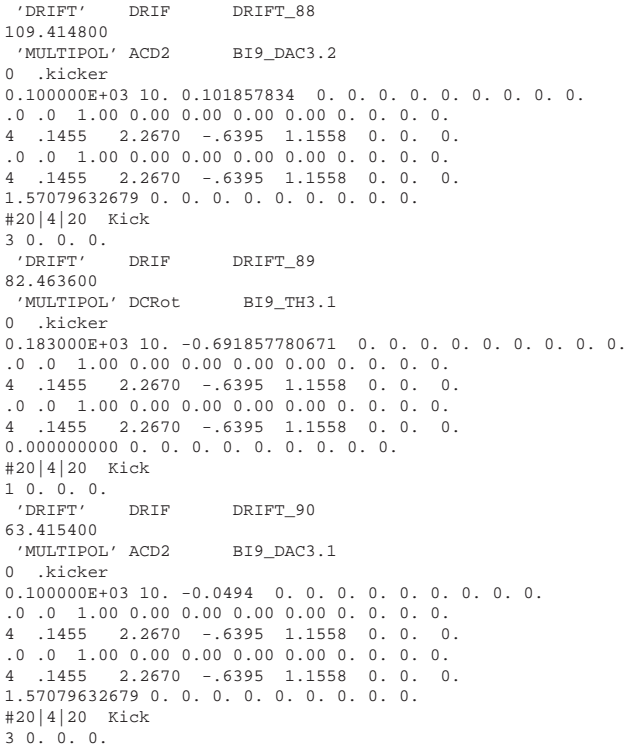

DRIF $\quad$ DRIFT 88 'MULTIPOL'
.kicker
$0.1000000^{2}$

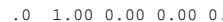

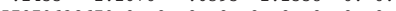
$\$ 20|4| 20$ Kick

'MULTIPOL' DCRot BI9_TH3.1

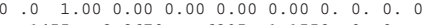
$\begin{array}{llll}.0 & .0 & 1.00 & 0.00 \quad 0.00\end{array}$

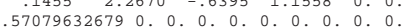
\$.

- DC rotators and AC dipoles input data, store :

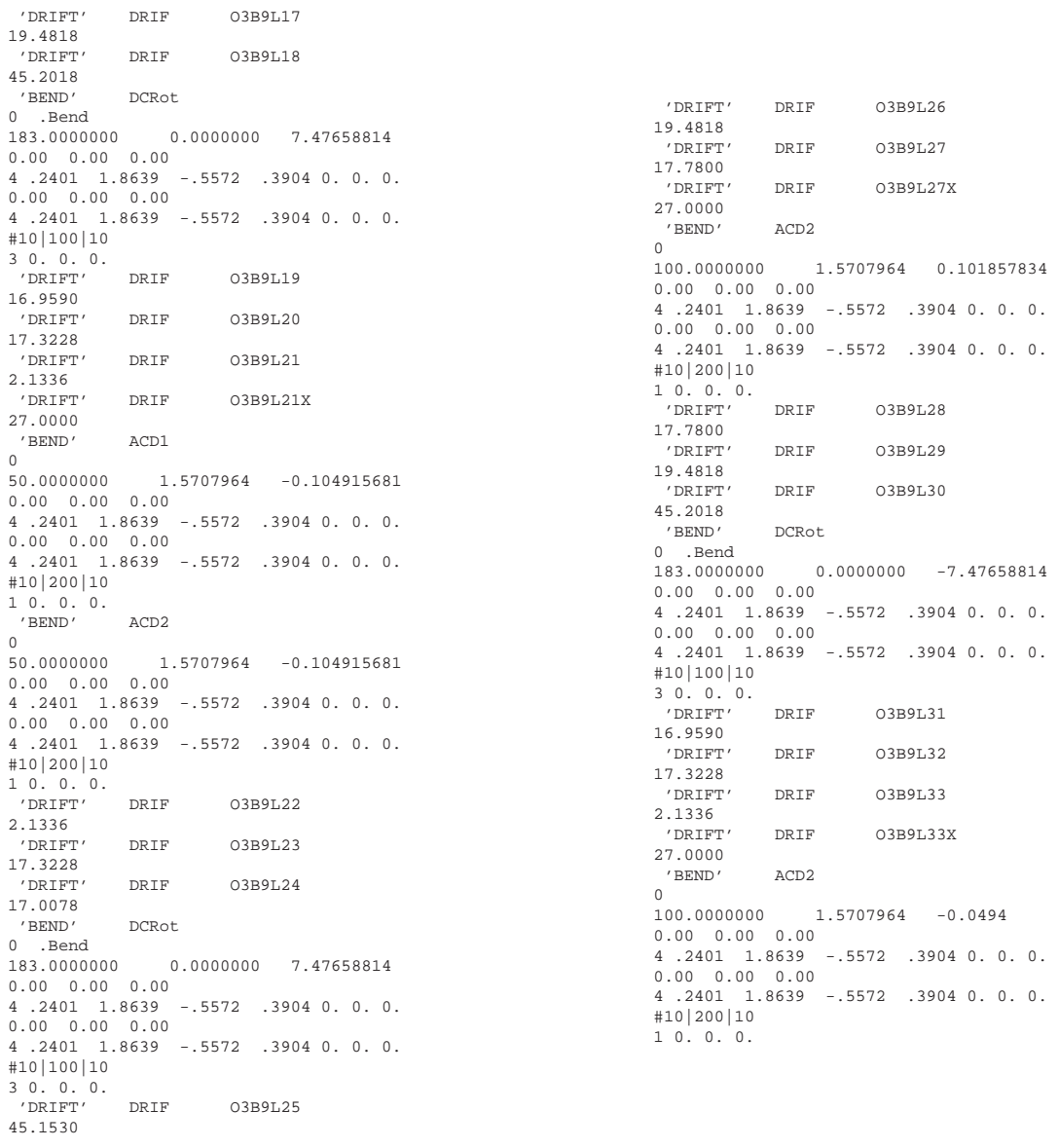




\section{Numerical outcomes}

\subsection{Injection $(\mathrm{G} \gamma=45.5)$}

Fig. 2 shows the two optics tracked, regular Run 17 lattice (left plot), and D' lattice (right) using the gamma transition patch translated from RHIC MADX model. $\Delta \mathrm{D}^{\prime}$ can easily be changed by tweaking a sensitive one of the $\gamma_{\mathrm{tr}}$ quadrupole families [1] - this is done here regardless of possible $\delta \beta / \beta$ betatron modulation however that tweak is small. Separation bumps at all IPs have been zeroed in the simulations, the orbit is flat. Snakes are simulated using "SPINR", pure spin rotation, no local orbit bump.

D' at snakes 1 and 2 takes the following values :

$\diamond$ without transition gamma quadrupole patch :

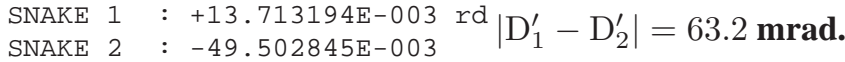

\section{$\diamond$ with transition gamma quadrupole patch, typical :}

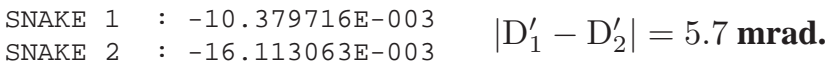

Spin flip has been tracked with several different $\Delta \mathrm{D}^{\prime}$ values. Note that in the non-D' lattice case $\Delta \mathrm{D}^{\prime}=63 \mathrm{mrad}<70 \mathrm{mrad}$, so that in the presence of $\mathrm{dp} / \mathrm{p}<1.5 \times 10^{-3}$ it ensures, as seen earlier, $\delta \mathrm{Q}_{\mathrm{s}}<1.5 \times 10^{-3}$, smaller than the $\Delta \mathrm{Q}_{\mathrm{osc}}=0.02$ span considered here, so partial flip can be expected.

Optical functions, from MADX twiss.out

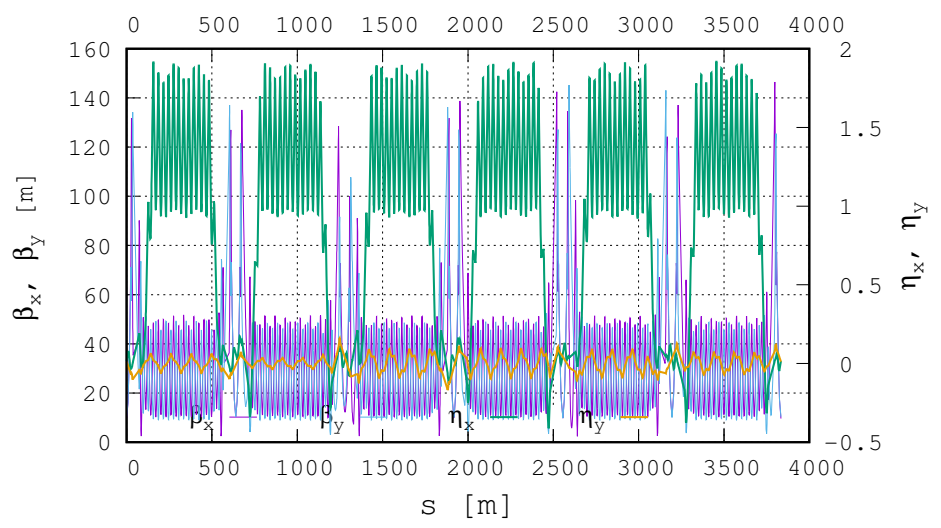

Optical functions, from MADX twiss.out

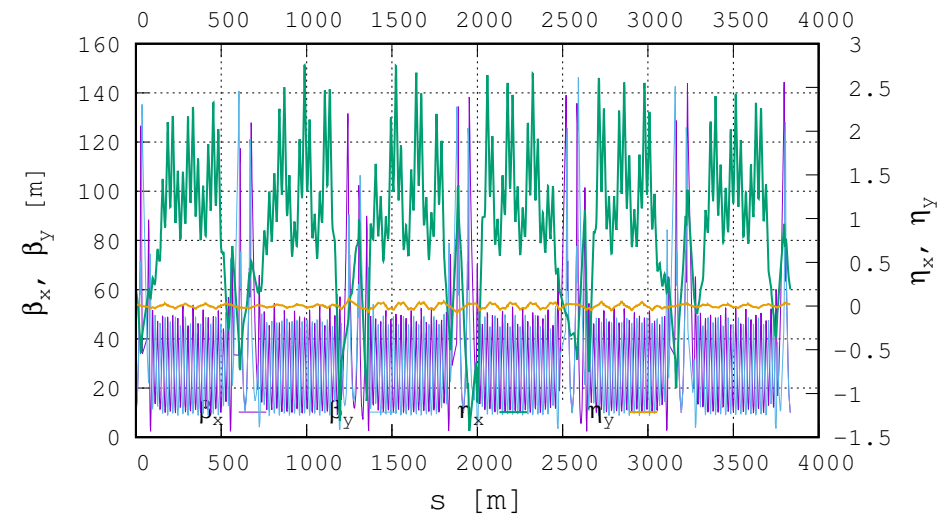

Figure 2: Blue injection optics, without (left) and with (right) D' lattice transition gamma quadrupole patch. In both cases, vertical separation bumps at IPs have been zeroed, here as well as in the flip simulations.

In addition :

- RF frequency is $9 \mathrm{MHz}$,

- 960 particles are tracked, Gaussian-distributed (truncated) in a 6-D bunch, polarization is computed as an average over that ensemble,

- particles possibly lost in some cases (due to purposely large/long bunch, in small number anyway) are not counted in the average polarization.

Orbit : possible residual orbit induced by the spin flipper (case of DC or AC bumps not strictly locally closed) may have a deleterious effect on the resonance crossing [3]. The two figures below show the horizontal and vertical orbits in the course of a sweep in the present simulations, namely, negligible orbital motion (at a few micro-meter level at IP6, about two orders of magnitude smaller than the betatron excursions of the particles).
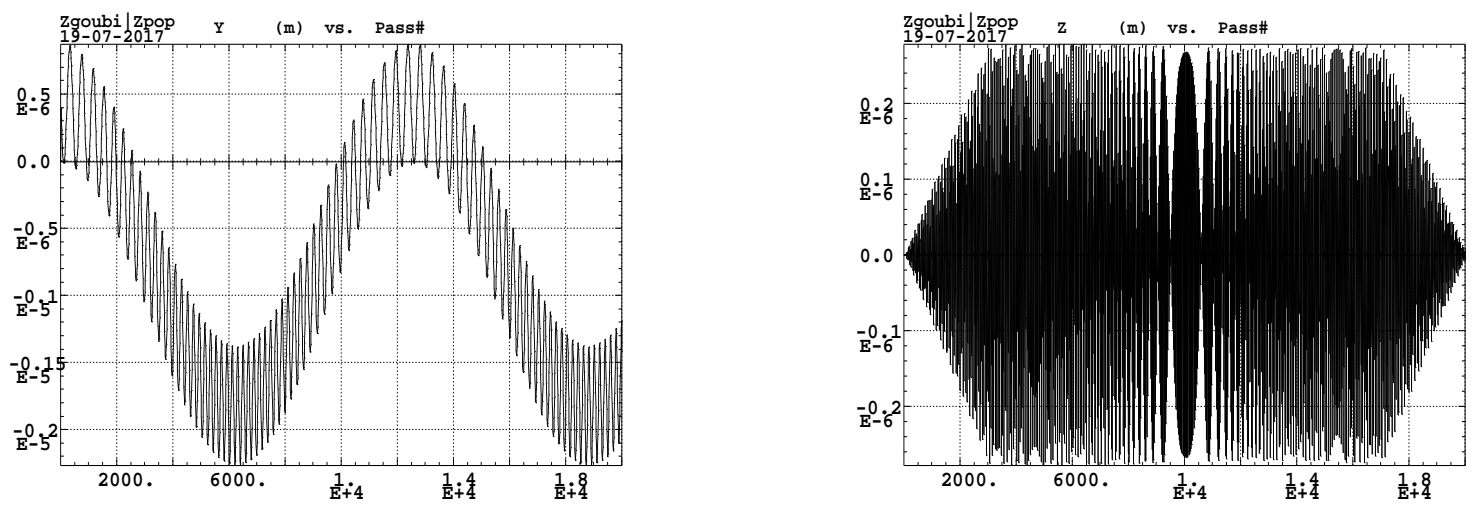

Orbital motion observed at IP6 (left : horizontal, right : vertical), in the conditions of the "regular optics" $\Delta \mathrm{Q}_{\mathrm{osc}}$ sweep of pp. 8, 9. The $9 \mathrm{MHz}$ RF $6 \mathrm{~Hz}$ synchrotron oscillation (13,000 turns about) is apparent on the left graph.

In both cases the residual orbit is marginal, well below $1 \mu \mathrm{m}$. 
Multiple crossing has been identified as a possible cause for polarization loss during the $\mathrm{Q}_{\mathrm{osc}}$ sweep, this is sketched in the figures on the right (with simulation conditions of page 8).

However, a $\Delta \mathrm{Q}_{\mathrm{osc}}=0.02$ sweep in $\approx 15,000$ turns, with $9 \mathrm{MHz} \mathrm{RF}$, is about one synchrotron period :

$$
\Omega_{\mathrm{s}}=\frac{\mathrm{c}}{\mathrm{R}} \sqrt{\frac{\mathrm{h} \eta \cos \left(\phi_{\mathrm{s}}\right) \mathrm{q} \hat{\mathrm{V}}}{2 \pi \mathrm{E}_{\mathrm{s}}}}
$$

Here, $\mathrm{R}=3833.8 \mathrm{~m}, \mathrm{~h}=120(9 \mathrm{MHz}), \eta=25.4^{-2}-0.002=-4.5 \times 10^{-4}$, $\cos \left(\phi_{\mathrm{s}}\right)=-1, \mathrm{q} \hat{\mathrm{V}}=20 \mathrm{keV}, \mathrm{E}_{\mathrm{s}}=23.8 \mathrm{GeV}$, so that $\Omega_{\mathrm{s}} / 2 \pi \approx 6 \mathrm{~Hz}$, $2 \pi / \Omega_{\mathrm{s}} \approx 12,000$ turns. As a consequence, a $10-20,000$ turn $\mathrm{Q}_{\mathrm{osc}}$ sweep as considered in the simulations, $1 \sim 2$ synchrotron oscillations, limits the possible number of crossings during the sweep (top figure on the right).

Instead, $28 \mathrm{MHz}, 200 \mathrm{kV} \mathrm{RF}, \Omega_{\mathrm{s}} / 2 \pi \approx 36 \mathrm{~Hz}, 2 \pi / \Omega_{\mathrm{s}} \approx 2,200$ turns, yields conditions more prone to multiple crossing, bottom figure on the right. This is confirmed by simulations (see Ref. [7] for instance).
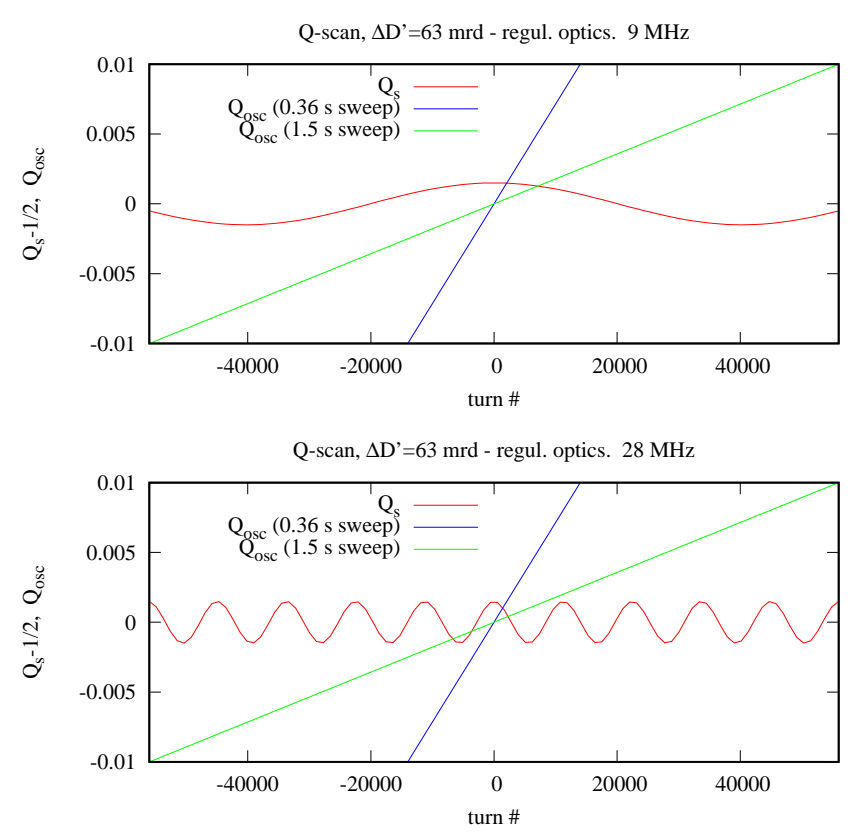

The next pages 8-9 give sample spin flip simulation results (simulations performed on NERSC [9]), for various $\Delta \mathrm{D}^{\prime}$ values and sweep durations. The graphics displayed include spin motion across the resonance for a 50-particle sample (red dots), and the average polarization over 960 particles (blue curves), as well as orbital motion monitoring of the 6-D bunch tracked.

Beyond showing the efficiency improvement with increased sweep rate, the tracking results in page 9 are an indication that spin flip can be obtained with $\Delta D^{\prime}$ substantially different from zero - at least in the defect free, perfect flipper setting conditions of these simulations. 
- REGULAR OPTICS ( $\Delta D^{\prime}=63$ mrad), TWO DIFFERENT SWEEP DURATIONS. RF 9 MHz -

(Red dots : sample trajectories. Blue curves : average over $\sim 960$ particles)

The two plots below show that the simulations yield substantial spin flip efficiency, in spite of a large $\Delta D^{\prime}$ value (regular Run 17 lattice).

- REGULAR OPTICS, SWEEP 20,000 TURNS

$S_{\mathrm{y}}$ vs. turn\#, from zgoubi.fai. 6-D bunch, $\Delta \mathrm{D}^{\prime}=63 \mathrm{mrad}$ - regular optics

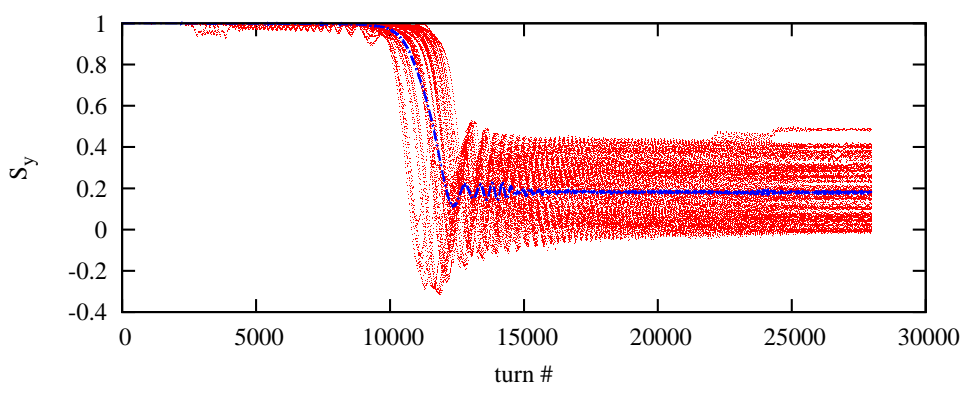

- REGULAR OPTICS, SWEEP 200,000 TURNS

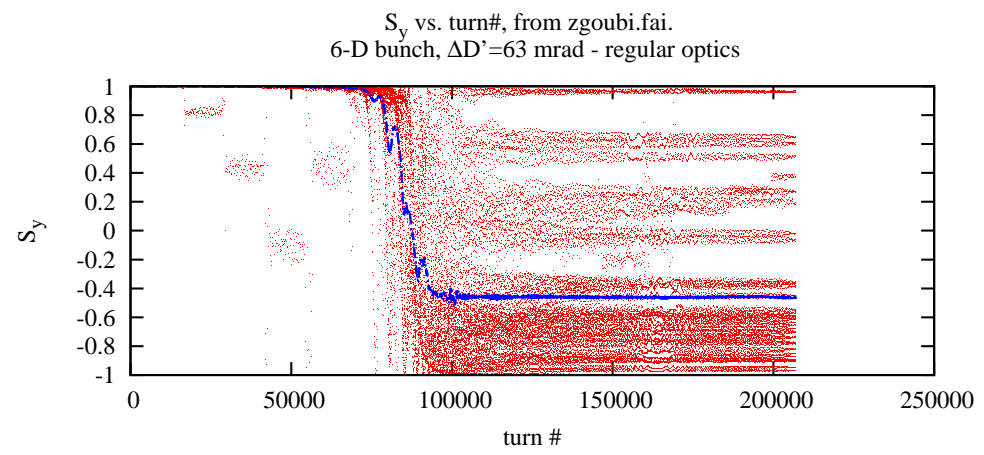

\section{- D' OPTICS, TWO DIFFERENT $\Delta \mathrm{D}^{\prime}$ VALUES. 9 MHz RF, 100,000 TURN SWEEP -}

(Red dots : sample trajectories. Blue curves : average over $\sim 960$ particles).

$\Delta \mathrm{D}^{\prime}$ is varied over a wide range here, it can be seen that the effect on the spin flip efficiency is small, with -0.837 at $\Delta \mathrm{D}^{\prime}=0.6 \mathrm{mrad}$ and -0.814 at $\Delta \mathrm{D}^{\prime}=13 \mathrm{mrad}$. Note that in both cases, 200,000 turns sweep ensures close to $100 \%$ spin flip efficiency (see $\Delta D^{\prime}=13 \mathrm{mrad}$ case above and next page ; more results in Tab. 1, p. 12).

- $\Delta \mathrm{D}^{\prime}=0.6 \mathrm{mrad}$

$S_{\mathrm{y}}$ vs. turn\#, from zgoubi.fai.

$6-\mathrm{D}$ bunch, $\Delta \mathrm{D}^{\prime}=0.6 \mathrm{mrd}$

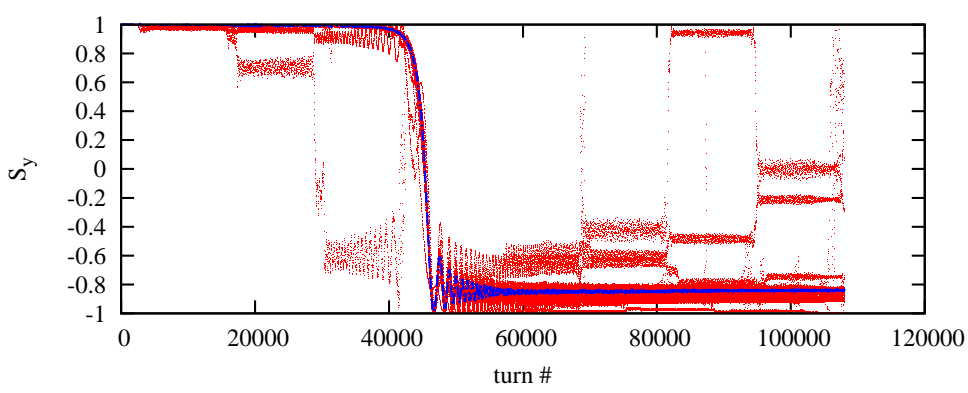

- $\Delta \mathrm{D}^{\prime}=13 \mathrm{mrad}$,

$S_{y}$ vs. turn\#, from zgoubi.fai. 6-D bunch, $\Delta \mathrm{D}^{\prime}=13 \mathrm{mrd}$

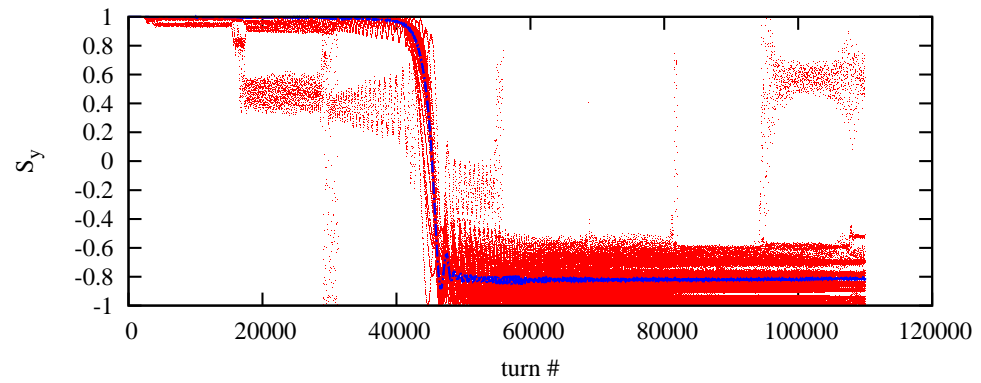

\section{$\diamond$ TYPICAL BUNCH AND RF CONDITIONS IN ZGOUBI :}

Bunch dimensions in the tracking simulations, above and next page, are about $1 \mu \mathrm{m}$ normalized rms emittance, transverse, $30 \mathrm{~ns}$ length and $\mathrm{dp} / \mathrm{p}= \pm 1.5 \times 10^{-3}$ momentum extent. Coordinates are taken Gaussian, truncated at $2 \sigma$ transverse. The three figures below show phase space motion of a few particles from the 960 particle bunch, during a sweep.

Some particles may be lost (this is apparent in the phase spaces below) depending on RF conditions such as voltage, however in a reduced number (a few percent), and in this case they are not taken into account in computing the average polarization. It has been observed (not shown here) that, taking a smaller bunch, half the transverse excursions displayed in the figures below, same longitudinal phase space, has marginal effect on final polarization.

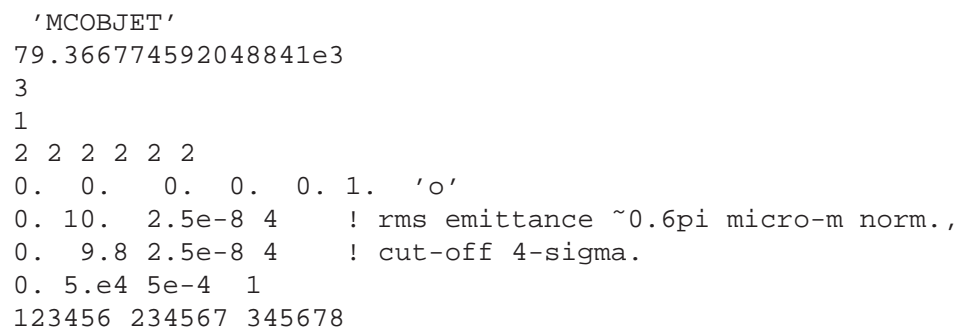

Typical transverse and longitudinal orbital motion, in these simulations :
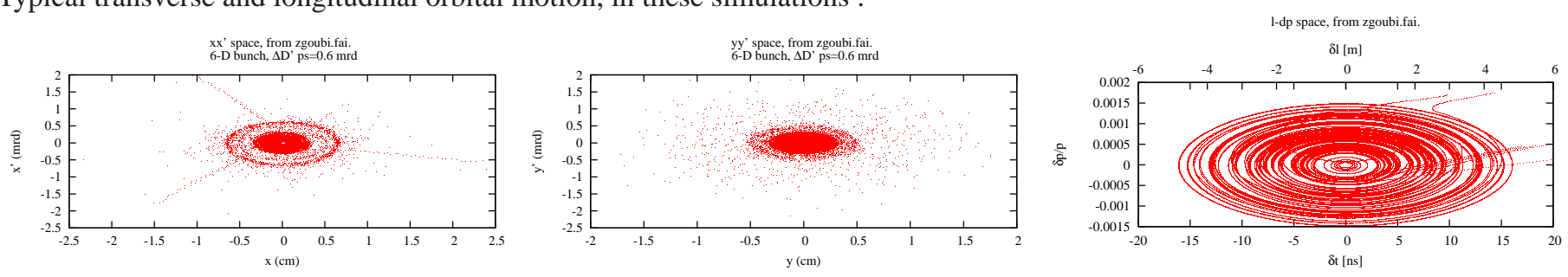
- INJECTION, D'=13 mrad, 9 MHz RF. FROM TOP TO BOTTOM : DECREASING SWEEP RATE TOWARDS $\mathrm{P}_{\mathrm{f}} / \mathrm{P}_{\mathrm{i}} \gg-1$ -

A systematic scan of the sweep rate is illustrated, showing the limits of slow sweep (multiple crossing, top plot) and fast sweep $\left(\mathrm{P}_{\mathrm{f}} / \mathrm{P}_{\mathrm{i}} \gg-1\right)$. With $\Delta D^{\prime}=13 \mathrm{mrad}$, a 200,000 turn sweep, 2.6 seconds, case of $\Delta Q_{\text {osc }}=0.02$, ensures spin flip, equivalent to 50,000 turns, 0.6 second about in the $\Delta Q_{\text {osc }}=0.005$ APEX conditions.

\section{- SWEEP 200,000 TURNS}

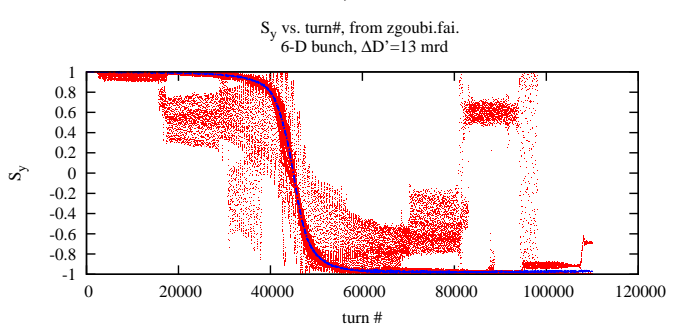

- SWEEP 100,000 TURNS

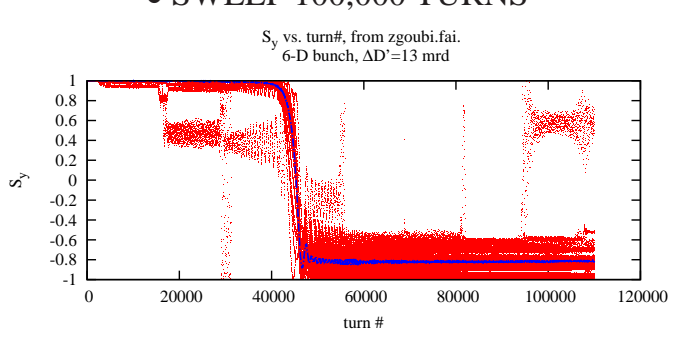

- SWEEP 50,000 TURNS

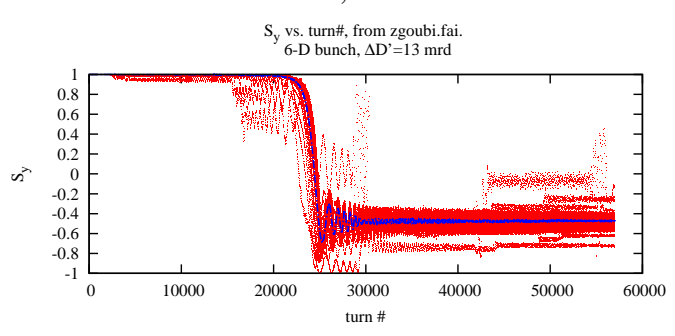

- SWEEP 10,000 TURNS

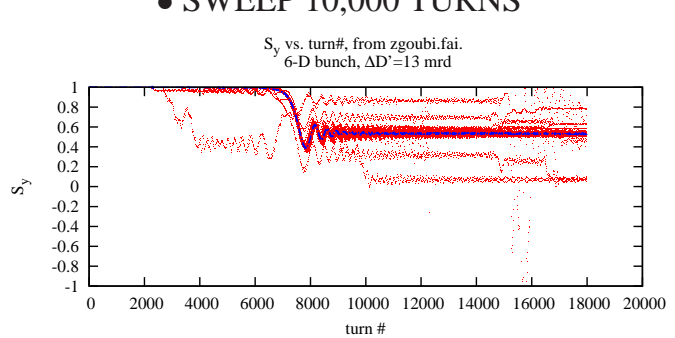

- SWEEP 2,000 TURNS

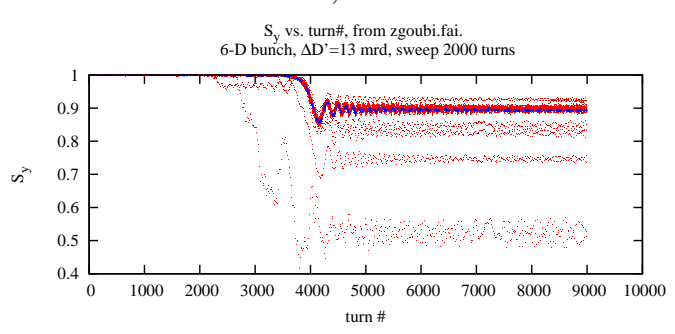

- A match (Fig. below) of $\left(\mathrm{P}_{\mathrm{f}}, \mathrm{P}_{\mathrm{i}}\right)$ data out of the simulations on the left, using

$$
\frac{\mathrm{P}_{\mathrm{f}}}{\mathrm{P}_{\mathrm{i}}}=2 \exp ^{-\frac{\pi}{2} \frac{|\epsilon|^{2}}{\alpha}}-1
$$

with $\alpha=\Delta \mathrm{Q}_{\mathrm{osc}} /(\mathrm{N} \times 2 \pi)$ and $\Delta \mathrm{Q}_{\mathrm{osc}}=0.51-0.49=0.02$, yields

$$
|\epsilon|=2.35402 \times 10^{-4}
$$

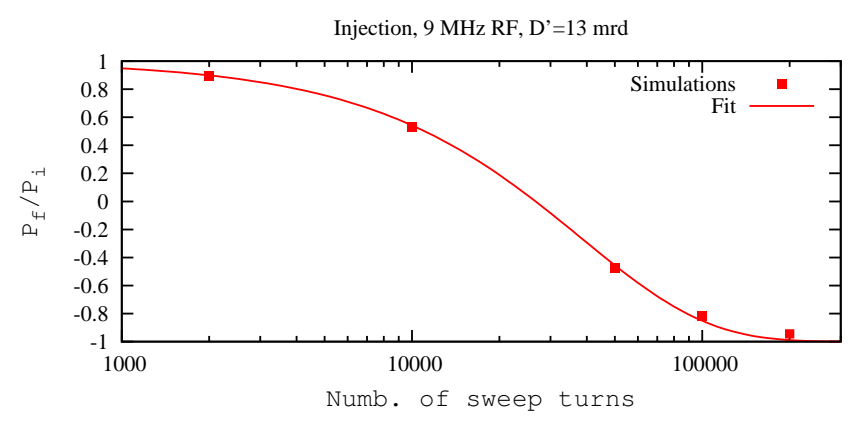

- On the other hand, the numerical simulation hypotheses, namely,

$$
\psi_{\mathrm{osc}}=(1+\mathrm{G} \gamma) \frac{\mathrm{B}_{\mathrm{osc}} \mathrm{L}}{\mathrm{B} \rho}=5.97 \times 10^{-3}
$$

given $\mathrm{G} \gamma=45.5, \mathrm{~B} \rho=79.4$ T.m, $\mathrm{B}_{\mathrm{osc}} \mathrm{L}=0.0102$ T.m, and

$$
\phi_{0}=(1+\mathrm{G} \gamma) \frac{\mathrm{BL}}{\mathrm{B} \rho}=0.5215 \mathrm{rd}, 29.9 \mathrm{deg}
$$

given $\mathrm{BL}=0.4866 \times 1.83$ T.m, yield a resonance strength value within $4 \%$ of the matched value above, namely

$$
\frac{\psi_{\text {osc }}}{\pi} \sin \phi_{0} \sin \frac{\phi_{0}}{2}=2.445 \times 10^{-4}
$$

- The Table below compares the present simulation conditions for $99 \%$ spin flip efficiency, and Run 17 APEX conditions :

\begin{tabular}{lcccccc}
\hline & $\mathrm{B}_{\mathrm{osc}} \mathrm{L}$ & $\phi_{0}$ & $\epsilon$ & $\Delta \mathrm{Q}_{\mathrm{osc}}$ & $\begin{array}{c}\text { minimal N } \\
\text { for }>99 \% \text { flip } \\
\text { (turns) }\end{array}$ & $\begin{array}{c}\text { duration } \\
\text { of the sweep } \\
(\mathrm{s})\end{array}$ \\
\hline simulations & 102 & 29.9 & 2.35 & 0.02 & 194,000 & 2.48 \\
APEX & 100 & 29.9 & 2.40 & 0.005 & 47,000 & 0.60 \\
\hline
\end{tabular}




\subsection{Store $(\mathrm{G} \gamma=487)$}

Fig. 3 shows typical D' optics conditions for these simulations, namely, taken from C-A/AP-478 [1]. Snakes are simulated using "SPINR", pure spin rotation, no local orbit bump.

D' values at snakes 1 and 2 in the original lattice are :

SNAKE $1:-21.041930 \mathrm{E}-003$

SNAKE $2:-18.937173 \mathrm{E}-003$

$$
\left|\mathbf{D}_{1}^{\prime}-\mathbf{D}_{2}^{\prime}\right|=2.1 \mathrm{mrad} .
$$

Note that $\Delta \mathrm{D}^{\prime}=2.1 \mathrm{mrad}<7 \mathrm{mrad}$, so that $\delta \mathrm{Q}_{\mathrm{s}}<\mathrm{dp} / \mathrm{p}$ (see page 4), well within $\Delta \mathrm{Q}_{\mathrm{osc}}=0.02$, a small amplitude which favors absence of multiple crossing.

Spin flipping has also been simulated for the following D' values :

SNAKE $1:-7.0955449 \mathrm{E}-004$

SNAKE $2:-2.3282297 \mathrm{E}-002$

$$
\left|\mathbf{D}_{1}^{\prime}-\mathbf{D}_{2}^{\prime}\right|=22.5 \mathrm{mrad} .
$$

and with $\Delta p / p \in\left[-3 \times 10^{-4},+3 \times 10^{-4}\right]$. In that case $\delta \mathrm{Q}_{\mathrm{s}}=\frac{\mathrm{G} \gamma}{\pi} \Delta \mathrm{D}^{\prime} \frac{\Delta \mathrm{p}}{\mathrm{p}} \approx \pm 10^{-3}$, well within the sweep $\Delta Q_{o s c}=0.02$.

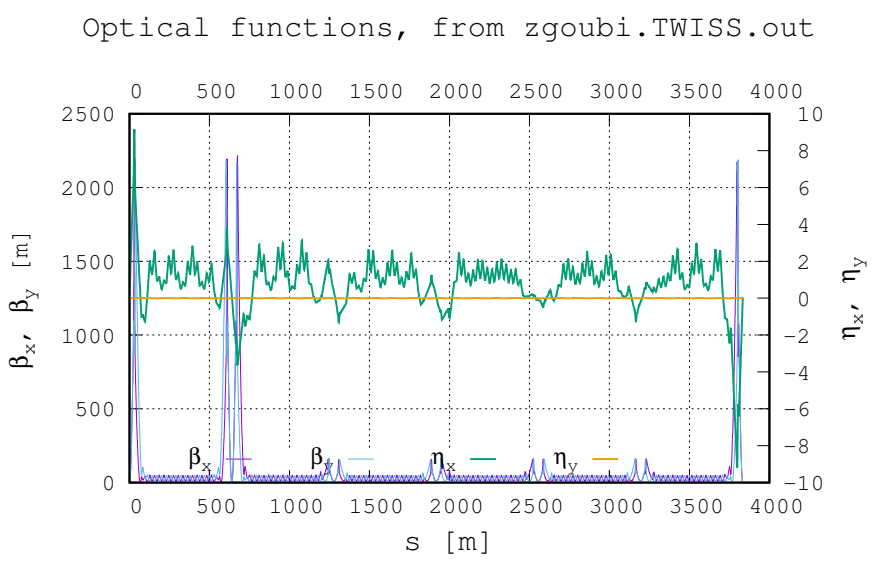

Figure 3: D' lattice optics used in C-A/AP-478.

The DC rotator and AC dipole settings in these store simulations are detailed in page 5.

In particular,

$\diamond$ AC dipole strength is set to 102 G.m (100 G.m in Run 17 APEX),

$\diamond \mathrm{DC}$ rotator strength is set to $45^{\circ}$ (48.8 $8^{\circ}$ in RHIC APEX) for appropriate resonance strength $\epsilon$ for full spin flipping,

$\diamond$ the ACD\#2-ACD\#4 $180^{\circ}+\phi_{0}$ phase relationship is set accordingly.

In addition :

- double RF frequency is considered here : $9+197 \mathrm{MHz}$, respectively $30 \mathrm{kV}$ and $15 \mathrm{kV}$ (data and figure below),

- 960 particles are tracked, polarization is the average over that ensemble,

- particles possibly lost (due to excessive bunch size) are not counted in the average polarization.

The next page gives spin flip simulation results (simulations performed on NERSC [9]), for various sweep durations.

The graphics displayed include spin motion across the resonance for a 50-particle sample (red dots), and the average polarization over 960 particles (blue).

\section{$\diamond$ TYPICAL BUNCH AND RF CONDITIONS IN ZGOUBI :}

Bunch dimensions in the tracking simulations, next page, are about $2.5 \mu \mathrm{m}$ normalized rms emittance, transverse, $30 \mathrm{~ns}$ length and dp/p $=$ $\pm 3 \times 10^{-4}$ momentum extent. Coordinates are taken Gaussian, transverse are truncated at $2 \sigma$. The figure below shows longitudinal phase space motion of a few particles from the 960 particle bunch, during a sweep.

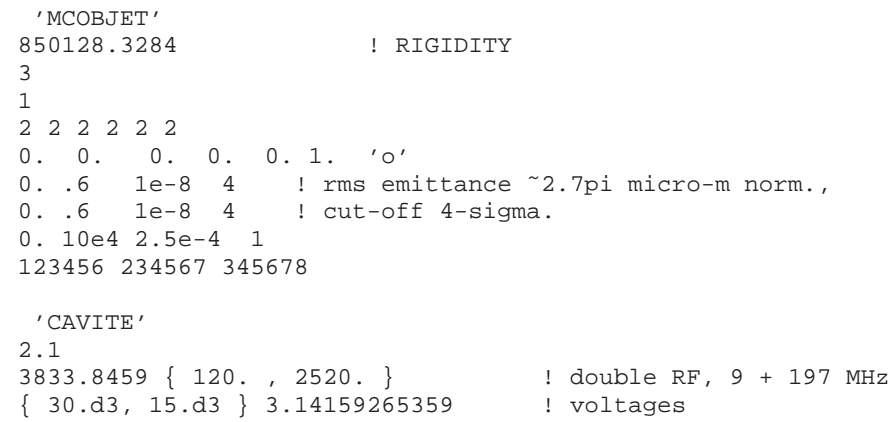

! double RF, 9 + $197 \mathrm{MHz}$ ! voltages

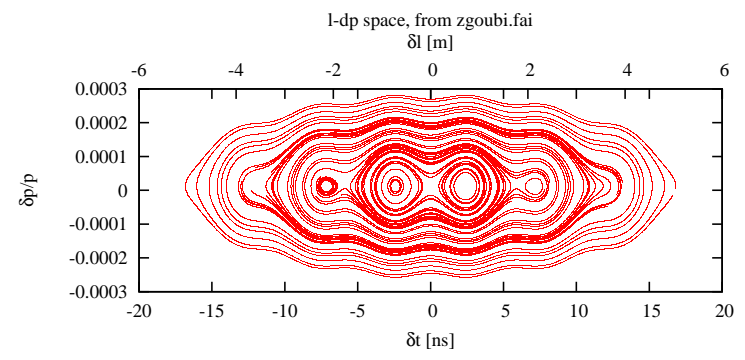

Longitudinal motion, typical. 


\section{- STORE, D'=22.5 mrad, DOUBLE-RF 9 + $197 \mathrm{MHz}(30$ + $15 \mathrm{kV})$ - \\ FROM TOP TO BOTTOM : INCREASING SWEEP RATE, UP TO CAUSING $\mathrm{P}_{\mathrm{f}} / \mathrm{P}_{\mathrm{i}} \gg-1$ -}

With $\Delta D^{\prime}=22.5 \mathrm{mrad}$, a 40,000 turn sweep, 0.5 seconds, ensures spin flip, equivalent to about 8,000 turns, 0.11 second, in the $\Delta Q_{\text {osc }}=0.005$ APEX conditions.

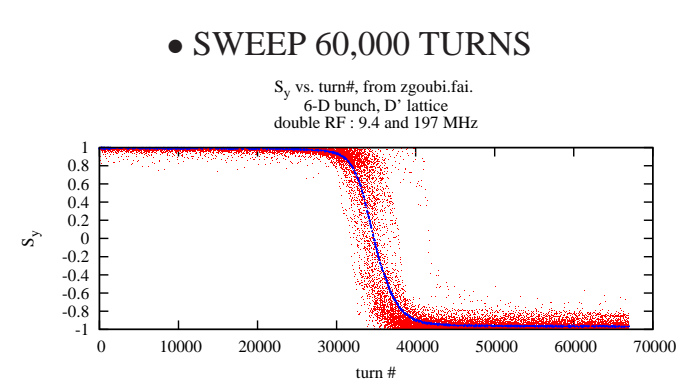

- SWEEP 28,000 TURNS

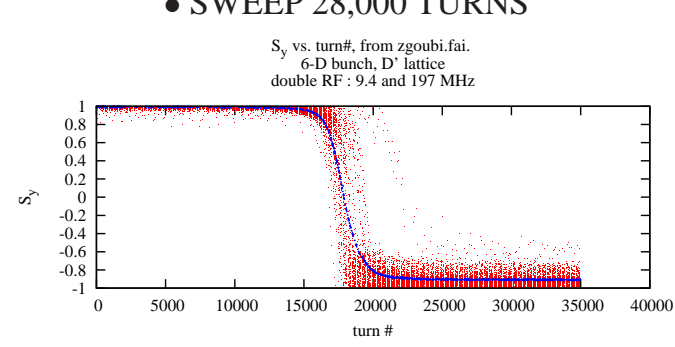

- SWEEP 5,000 TURNS

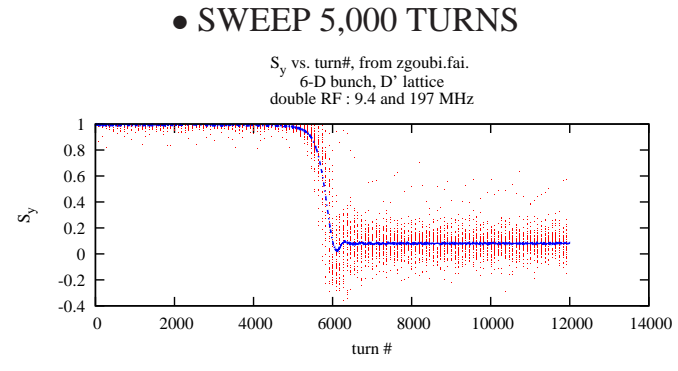

- SWEEP 1,000 TURNS

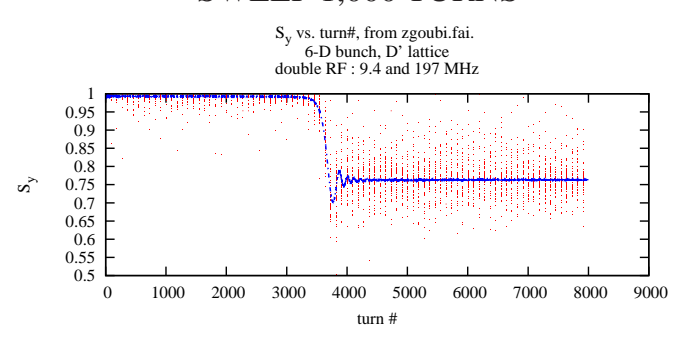

- SWEEP 500 TURNS

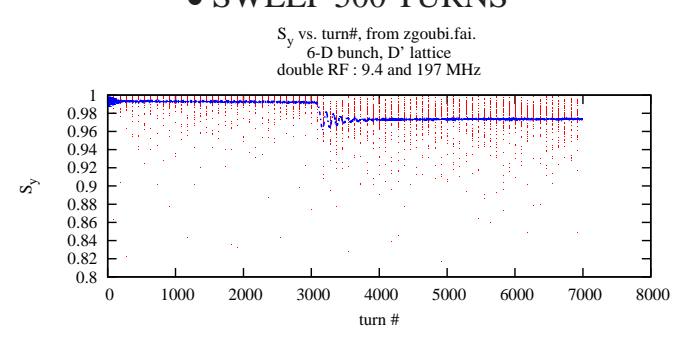

- A match (Fig. below) of $\left(\mathrm{P}_{\mathrm{f}}, \mathrm{P}_{\mathrm{i}}\right)$ data out of the simulations on the left, using

$$
\frac{\mathrm{P}_{\mathrm{f}}}{\mathrm{P}_{\mathrm{i}}}=2 \exp ^{-\frac{\pi}{2} \frac{|\epsilon|^{2}}{\alpha}}-1
$$

with $\alpha=\Delta \mathrm{Q}_{\mathrm{osc}} /(\mathrm{N} \times 2 \pi)$ and $\Delta \mathrm{Q}_{\mathrm{osc}}=0.51-0.49=0.02$, yields

$$
|\epsilon|=5.15757 \times 10^{-4}
$$

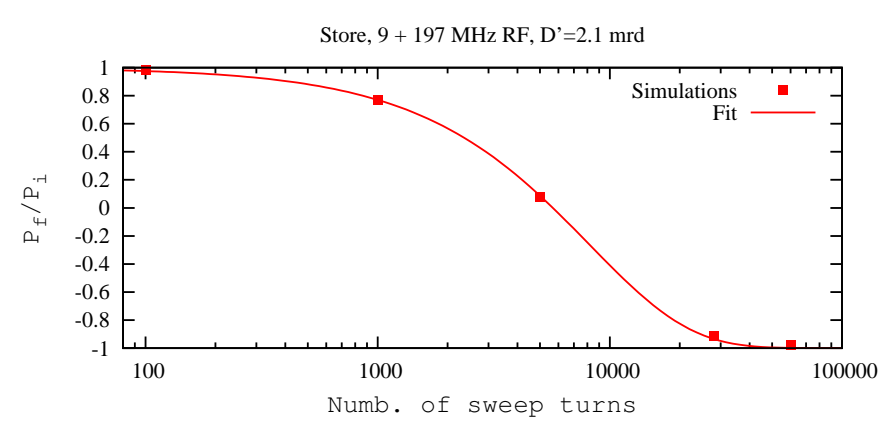

- On the other hand, the numerical simulation hypotheses, namely,

$$
\psi_{\mathrm{osc}}=(1+\mathrm{G} \gamma) \frac{\mathrm{B}_{\mathrm{osc}} \mathrm{L}}{\mathrm{B} \rho}=5.86 \times 10^{-3}
$$

given $\mathrm{G} \gamma=487, \mathrm{~B} \rho=850$ T.m, $\mathrm{B}_{\mathrm{osc}} \mathrm{L}=0.0102$ T.m, and

$$
\phi_{0}=(1+\mathrm{G} \gamma) \frac{\mathrm{BL}}{\mathrm{B} \rho}=0.5215 \mathrm{rd}, 45.1 \mathrm{deg}
$$

given $\mathrm{BL}=0.7476 \times 1.83 \mathrm{~T}$.m, yield a resonance strength value within $2 \%$ of the matched value above, namely

$$
\frac{\psi_{\mathrm{osc}}}{\pi} \sin \phi_{0} \sin \frac{\phi_{0}}{2}=5.06345 \times 10^{-4}
$$

- The Table below compares the present simulation conditions for $99 \%$ spin flip efficiency, and Run 17 APEX conditions :

\begin{tabular}{lcccccc}
\hline & $\mathrm{B}_{\mathrm{osc}} \mathrm{L}$ & $\phi_{0}$ & $\epsilon$ & $\Delta \mathrm{Q}_{\mathrm{osc}}$ & $\begin{array}{c}\text { minimal N } \\
\text { for >99\% flip } \\
\text { (turns) }\end{array}$ & $\begin{array}{c}\text { duration } \\
\text { of the sweep } \\
(\mathrm{s})\end{array}$ \\
\hline simulations & 102 & 45.1 & 5.16 & 0.02 & 40,400 & 0.52 \\
APEX & 100 & 48.8 & 5.68 & 0.005 & 8,300 & 0.11 \\
\hline
\end{tabular}




\subsection{A summary table}

Table 1 below summarizes results obtained for typical cases amongst the various spin flip simulations performed.

The quantities varied here are $\Delta \mathrm{D}^{\prime}$ and the number of turns of the sweep. Other parameters : RF frequency and voltage, $\Delta \mathrm{Q}_{\mathrm{osc}}$, bunch size, etc., are as specified earlier at either injection, with in particular momentum spread $\Delta \mathrm{p} / \mathrm{p} \in\left[-1.5 \times 10^{-3},+1.5 \times 10^{-3}\right]$ (Sec. 3.1) or store with momentum spread $\Delta \mathrm{p} / \mathrm{p} \in\left[-3 \times 10^{-4},+3 \times 10^{-4}\right]$ (Sec. 3.2).

Note that due to the large beam size, in particular large momentum spread, up to $10 \%$ of the beam is lost in the 200,000 tracking cases. Large momentum spread could be the cause for the maximum efficiency of about $95 \%$ found in the $0.6-13 \mathrm{mrad}$ range, this is to be investigated further.

Table 1: A summary of $\mathrm{P}_{\mathrm{f}} / \mathrm{P}_{\mathrm{i}}$ values in some of the spin flip simulations performed. Initial polarization $\mathrm{P}_{\mathrm{i}}$ is taken at the end of the 3000 turn AC-dipole up ramp, final polarization $\mathrm{P}_{\mathrm{f}}$ is the asymptotic value after the $\Delta \mathrm{Q}_{\mathrm{osc}}$ sweep.

\begin{tabular}{|c|c|c|c|c|c|}
\hline \multicolumn{6}{|l|}{ Injection } \\
\hline \multirow[t]{2}{*}{$\mathrm{D}^{\prime}(\mathrm{mrad})$} & \multicolumn{5}{|c|}{ Number of turns of the ACD sweep } \\
\hline & 200,000 & 100,000 & 50,000 & 20,000 & 10,000 \\
\hline 0.6 & $-0.947 / 0.9995$ & $-0.837 / 0.9995$ & & & \\
\hline 4.8 & $-0.946 / 0.9995$ & & & & \\
\hline 13 & $-0.944 / 0.9995$ & $-0.814 / 0.9995$ & $-0.472 / 0.9995$ & & $0.53 / 0.9995$ \\
\hline 63 & $-0.449 / 0.9995$ & & & $+0.180 / 0.9995$ & \\
\hline \multicolumn{6}{|l|}{ Store } \\
\hline \multirow[t]{2}{*}{$\mathrm{D}^{\prime}$ (mrad) } & & Number of turns & ff the ACD sweep & & \\
\hline & 60,000 & 28,000 & 5,000 & 1,000 & \\
\hline 0.0 & -0.985 / 0.992 & & & & \\
\hline 2.1 & $-0.982 / 0.992$ & $-0.924 / 0.992$ & & & \\
\hline 22.5 & -0.967 / 0.992 & $-0.908 / 0.992$ & $+0.080 / 0.992$ & $+0.763 / 0.992$ & \\
\hline
\end{tabular}

As summarized in Tab. 1, the simulations show weak dependence of spin flip efficiency on $\Delta \mathrm{D}^{\prime}$, namely (figure below),

- at injection, efficiency $\approx 94 \sim 95 \%$ over the range explored $0.6 \leq\left|\Delta \mathrm{D}^{\prime}\right| \leq 13 \mathrm{mrad}$,

- at store, efficiency $\approx 97 \sim 99 \%$ over the range explored $0 \leq\left|\Delta \mathrm{D}^{\prime}\right| \leq 22 \mathrm{mrad}$.

For the record, the number of turns of the "fast sweep", respectively 200.000 and 60,000 , has been determined by its yielding, in theory, $99 \%$ spin flip, see bottom right tables in pp. 9 and 11 respectively.

These results seem in contradiction with APEX measurements : polarization is lost during the sweep if $\Delta D^{\prime}$ is not at mrad level or less [10, 11]. This needs further investigation.

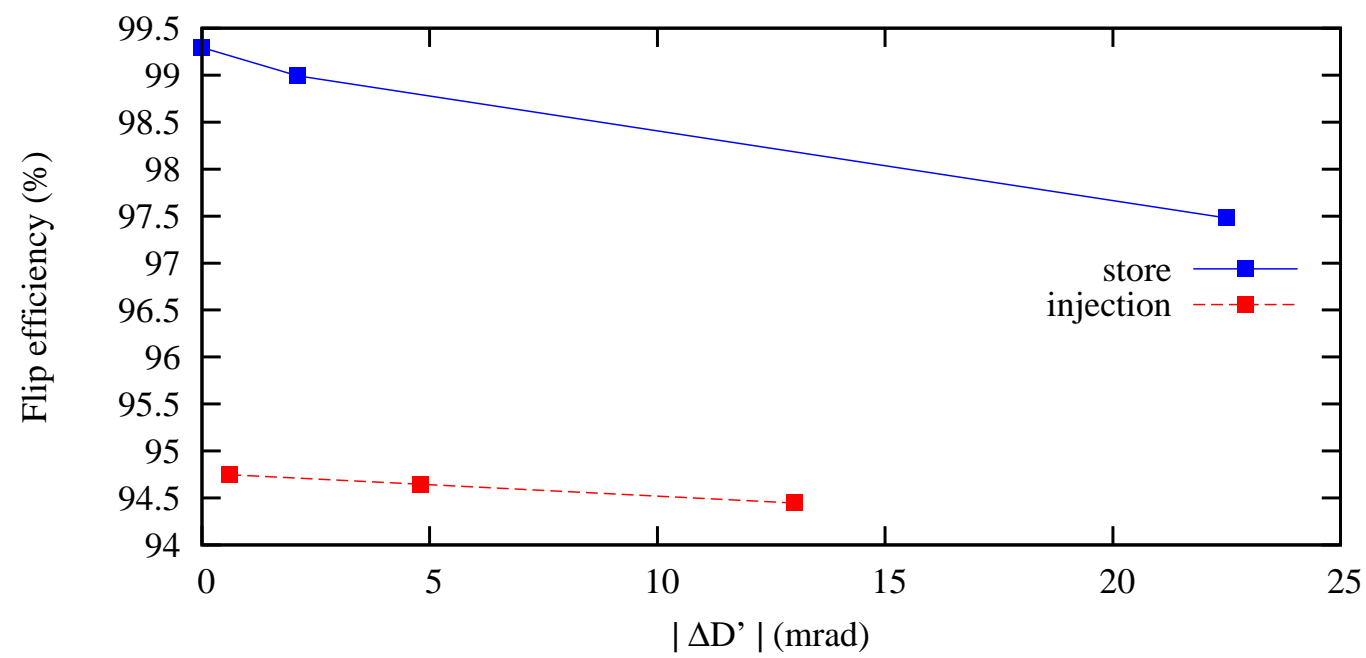

$\Delta \mathrm{D}^{\prime}$ dependence of spin flip efficiency. 


\section{Conclusions}

These simulations show the following :

(i) All the simulations performed (much more than summarized in this note), covering various $\Delta \mathrm{D}^{\prime}$ values including non-D' lattice, various $\mathrm{RF}$ frequencies including double RF, various transverse and longitudinal beam sizes up to such sizes as to generate dynamical beam loss, show improved flip efficiency with resonance crossing speed $\alpha=\Delta \mathrm{Q}_{\mathrm{osc}} / 2 \pi \mathrm{N}$ on the high side.

This has been confirmed experimentally,

- in a first trial at injection, $\mathrm{G} \gamma=45.5$, with sweep time decreased from 3 second as in usage (about 235,000 turns for a frequency span of 0.005 , i.e., $\left.\Delta \mathrm{Q}_{\mathrm{osc}} / \Delta \mathrm{t}=0.005 / 3=0.0017 \mathrm{~s}^{-1}\right), 92 \%$ flip efficiency, down to $1 \mathrm{sec}\left(0.005 \mathrm{~s}^{-1}\right)$ and further to $0.5 \mathrm{sec}\left(0.01 \mathrm{~s}^{-1}\right)$ both yielding $97.5 \%$ flip instead [10],

- in a second trial at store, $\mathrm{G} \gamma=487$, with a flip efficiency of $90 \%$ for a 1 second sweep, and $97 \%$ for 0.5 second sweep [11] with no indication that the latter is a lower limit.

(ii) APEX measurements at injection [10] show an optimal sweep between 0.5 and 1 second, in accord with simulations which yield $\approx 0.6$ second for $99 \%$ flip efficiency given the APEX $\Delta Q_{\text {osc }}$ value (page 9). APEX measurements at store [11] indicate that the sweep duration could be decreased further below 0.5 second, in accord with simulation data that yield an optimal $\approx 0.11$ second sweep for $99 \%$ flip efficiency given the APEX $\Delta \mathrm{Q}_{\mathrm{osc}}$ and $\phi_{0}$ values (page 11).

The optimum is between two limits : number of turns $\mathrm{N}$ small enough (greater $\alpha$ ) to avoid multiple crossing, large enough (smaller $\alpha$ ) to ensure $2 \exp \left(-\frac{\pi}{2} \frac{|\epsilon|^{2}}{\alpha}\right)-1 \approx-1$.

(iii) The numerical simulations show significant tolerance on $\Delta \mathrm{D}^{\prime}$, in the limit that $\delta \mathrm{Q}_{\mathrm{s}}$ (Eq. 6) is maintained well within $\Delta \mathrm{Q}_{\mathrm{osc}}$ sweep range. This is illustrated in the injection case, $\Delta \mathrm{D}^{\prime} \leq 13 \mathrm{mrad}$ (p. 8 and Tab. 1, p. 12), which satisfies $\Delta \mathrm{D}^{\prime}<70 \mathrm{mrad}$ so maintaining $\delta \mathrm{Q}_{\mathrm{s}}<\delta \mathrm{p} / \mathrm{p} \approx$ $1.5 \times 10^{-3}$ (bottom right plot in p. 8). In a similar manner at store, simulations with $\Delta \mathrm{D}^{\prime}$ up to $22 \mathrm{mrad}\left(\delta \mathrm{Q}_{\mathrm{s}} \approx 3.4 \times \Delta \mathrm{p} / \mathrm{p} \approx 0.001\right)$ yield high efficiency spin flip (p. 11 and Tab. 1).

The numerical simulations indicate one thing in that respect :

- a non-small $\Delta \mathrm{D}^{\prime}$ value may not be in itself an overriding cause of the poor flip efficiency which seems correlatively obtained in the experiments : the mechanism of multiple crossing that large D' contributes inducing may be overcome for instance by faster sweep as discussed in (i) and (ii). Tests were planned at $255 \mathrm{GeV}$ during the latest APEX, based on the fact that a $40 \%$ flip efficiency had been obtained with 3 second sweep (and $\left|\Delta \mathrm{D}^{\prime}\right|=3 \mathrm{mrad}$ ) [11], a value expected to be substantially improved with faster sweep, however APEX time allotted, time spent on tuning $\Delta \mathrm{D}^{\prime}$ optics, and other machine downtime did not allow verifying that.

Understanding the details of these spin flip dynamics simulations, and answering the various questions they raise, will require more investigations. This includes, as part of the plans, more simulations in the very spin flipper and bunch conditions of Run 17 APEX. 


\section{References}

[1] J. Kewisch et al., Correction of the spin chromaticity in RHIC, C-A/AP/478 (2013).

[2] M. Bai and T. Roser, Full Spin Flipping in the Presence of Full Siberian Snake, Phys. Rev. ST Accel. Beams 11, 091001 (2008).

[3] S. R. Mane, Comment on "Full spin flipping in the presence of full Siberian Snake", Phys. Rev. ST Accel. Beams 12, 099001 (2009).

[4] M. Bai, W. W. MacKay, and T. Roser, Comment on "Spin manipulation of 1:94 GeV=c polarized protons stored in the COSY cooler synchrotron”, Phys. Rev. ST Accel. Beams 12, 099001 (2009).

[5] Rhic Spin Flipper Project Status, M. Bai, C. Dawson, J. Kewisch, A. A. Poblaguev, P. Oddo, Brookhaven National Laboratory, Upton, NY (2015)

[6] M. Bai et al., Impact on Spin Tune From Horizontal Orbital Angle Between Snakes and Orbital Angle Between Spin Rotators, C-A/AP/334 $(10 / 1 / 2008)$.

[7] RHIC SPIN FLIPPER STATUS AND SIMULATION STUDIES, M. Bai et al., Procs. 2011 PAC, NY.

[8] The ray-tracing code Zgoubi, F. Méot, NIM A 767 (2014) 112-125.

https://zgoubi.sourceforge.io/ZGOUBI_DOCS/Zgoubi.pdf

[9] NERSC computing, on web : http://www.nersc.gov/

[10] H. Huang, Spin meeting minutes, 26 May 2017, BNL C-AD. http://www.cadops.bnl.gov/AP/spinmeeting.htm

[11] H. Huang, Spin meeting minutes, 27 July 2017, BNL C-AD. http://www.cadops.bnl.gov/AP/spinmeeting.htm 